Brit. F. vener. Dis. (1972) 48, 141

\title{
Persistence of spermatozoa in the vagina and cervix
}

\author{
A. I. MORRISON \\ Special Treatment Centre, Queens Road, Barnsley, Yorkshire
}

In the course of routine investigations of women patients attending special treatment clinics, spermatozoa are sometimes noted as an incidental finding in smears taken from the vagina and cervix. The presence of sperms in the female lower genital tract, and estimation of the longest interval after coitus at which they can still be found there may be of forensic importance, clinical significance, or academic interest.

Smith and Cook (1928) state that spermatozoa may remain in the posterior fornix for as long as $\mathbf{1 7}$ days, and may survive a menstrual period. In the British Medical fournal (1964a), it is stated that live sperms have been found in the cervix 3 days after coitus. McLeod, Martens, Silberman, Sobrero, and Harrison (1958) assert that penetration of the cervical mucus by spermatozoa is related to the viscosity of the mucus, the physical properties of which are partly under the control of oestrogen. The viscosity is lowest, apparently, at mid-cycle, and penetration by spermatozoa seems to be easiest at this time. 'Cervical hostility' is defined as the failure of sperms to penetrate, or to survive within the cervical mucus, at the immediately pre-ovulatory phase of the menstrual cycle. This must be due to changes in viscosity in the mucus (Brit. med. F., 1964b). Rothschild (1962), in his Ingleby Lecture, discussed the chemotaxis, metabolism, morphology, and movement of spermatozoa generally, not only in man.

The routine followed in special clinics affords the opportunity of finding out how long after intercourse sperms could be found in the lower genital tract, and of studying the relation, if any, between coitus and the persistence of sperms and the menstrual cycle.

\section{Present investigations}

MATERIAL

The present study was carried out on 104 patients attending this clinic. The women were all white and their average age was 23.4 years.

\section{METHOD}

In each case the usual routine examination was made. Gram-stained smears from the urethra, cervix, and vagina, and a wet vaginal film were examined in the clinic. Films

Received for publication September 14, 1970 were sent to the laboratory for confirmation, with swabs in Stuart's medium for culture. Other films and cultures were taken where indicated, e.g. from Bartholin's ducts or Skene's tubules, or for the darkground examination of material from erosions and ulcers. A specimen of urine was tested for albumen and sugar and a specimen of blood was sent for routine serological tests for syphilis. In all, 178 examinations were carried out.

At each examination each patient was asked the date of her last menstrual period, and when coitus had last occurred. The time elapsing between coitus and taking smears is here termed the coital interval. The shortest coital interval was 2 hours, and the longest 21 days (Table I). The relation of coitus to the day of the menstrual cycle is referred to as the menstrual interval. In most cases it is given as the number of days after the end of the last period.

TABLE I Coital interval in 178 cases

\begin{tabular}{|c|c|}
\hline Coital interval (days) & No. of cases \\
\hline Less than 1 & 65 \\
\hline $1-3$ & 59 \\
\hline $4-7$ & 35 \\
\hline $8-14$ & 13 \\
\hline $15-21$ & 6 \\
\hline Total & 178 \\
\hline
\end{tabular}

The date of the last menstrual period was ascertained at 133 examinations. No date could be stated at 28 examinations because of pregnancy in six patients, total hysterectomy in two, and amenorrhoea in eight (7 of these patients were taking a contraceptive pill). In a further seventeen instances the patient was unable to remember the date of her last period. The longest menstrual interval was 28 days in a cycle of 33 days (Table II).

In the majority of of the 133 cases in which the date of the last menstrual period was known, the menstrual interval was less than 15 days. In 50 per cent. it was 7 days or less, in 21 per cent. it was between 8 and 14 days, in 13.5 per cent. between 15 and 21 days, and in 8.3 per cent. between 22 and 28 days. Intercourse occurred just before or during menstruation in 7 per cent. of cases. All the patients denied having used an occlusive contraceptive. 
TABLE II Menstrual interval in 133 cases

\begin{tabular}{|c|c|c|c|}
\hline Menstrual interval & & No. of cases & $\begin{array}{l}\text { Per } \\
\text { cent. }\end{array}$ \\
\hline $\begin{array}{l}\text { Coitus before last menstrual period } \\
\text { during last menstrual period } \\
\text { since last menstrual period }\end{array}$ & $\begin{array}{l}1-7 \text { days } \\
8-14 \text { days } \\
15-21 \text { days } \\
22-28 \text { days }\end{array}$ & $\begin{array}{r}6 \\
3 \\
67 \\
28 \\
18 \\
11\end{array}$ & $\begin{array}{l}7 \\
70 \\
21 \\
13 \cdot 5 \\
8 \cdot 3\end{array}$ \\
\hline Total & & 133 & $99 \cdot 8$ \\
\hline Interval not known & & 17 & \\
\hline No menstruation & & 28 & \\
\hline Total & & 178 & \\
\hline
\end{tabular}

\section{Results}

Spermatozoa were seen at 104 examinations out of the total of 178 (58.4 per cent.). They were seen in both vaginal and cervical smears on 27 occasions, in the vaginal slide alone 15 times, in the cervical slide alone 62 times, and on 74 occasions they were not found in either smear (Table III). The total number of times they were seen in smears from the cervix was 89 , and from the vagina 42 .

TAB LE III Positive findings in 178 examinations

\begin{tabular}{|c|c|c|c|c|}
\hline Site & $\begin{array}{l}\text { Cervix } \\
\text { only }\end{array}$ & $\begin{array}{l}\text { Vagina } \\
\text { only }\end{array}$ & $\begin{array}{l}\text { Cervix } \\
\text { and } \\
\text { vagina }\end{array}$ & Total \\
\hline $\begin{array}{l}\text { No. of cases } \\
\text { Per cent. }\end{array}$ & $\begin{array}{l}62 \\
34 \cdot 8\end{array}$ & $\begin{array}{c}15 \\
8 \cdot 4\end{array}$ & $\begin{array}{l}27 \\
15 \cdot 2\end{array}$ & $\begin{array}{c}104 \\
58 \cdot 4\end{array}$ \\
\hline
\end{tabular}

Positive results might depend on two factors: the coital interval and the menstrual interval. The results obtained were therefore related to both these factors in the 133 cases in which the menstrual interval was known (Table IV). It appeared that sperms persisted longest after intercourse in the first 14 days following a menstrual period. There was a marked progressive decrease in the number of positive results if smears were examined more than 48 hours after coitus. No positive results were obtained from the 10th day after coitus onwards, with the exception of one case in which sperms were present in a cervical smear 12 days after coitus on the 8th day after the cessation of the menstrual period. The longest interval after coitus at which spermatozoa were found in the vagina was 9 days, coitus having taken place 5 days after the end of the menstrual period. In the group of patients who did not know the date of the last period, sperms were found up to 7 days after intercourse. In the examination of pregnant patients, sperms were found in the cervix up to 48 hours after coitus, and in the vagina 7 days after coitus. (Harkness (1970) found sperms in the cervix of a pregnant woman 7 days after intercourse.)

When coitus took place on the day a menstrual period started, sperms were found in the cervix 5 days later in one case. In two cases in which coitus took place the day before the period finished sperms were found 3 and 5 days later respectively.

\section{Discussion}

These results indicate that the optimum interval for taking smears after coitus is up to 48 hours; after this time the positive results decrease progressively, though not regularly. With one exception on the 12th day, the results from the 10th day after coitus onwards were all negative.

Coitus occurred most frequently during the first 7 days after the menstrual period had finished (50 per cent.). There were not enough patients in each of the other 3 weeks to enable any conclusions to be reached on the effect of the menstrual cycle on the persistence of sperms in the cervix. A much larger number of patients examined over a longer period of time would supply the data required.

TABLE IV Positive results (as proportion of specimens examined) related to coital interval and menstrual interval in 133 cases

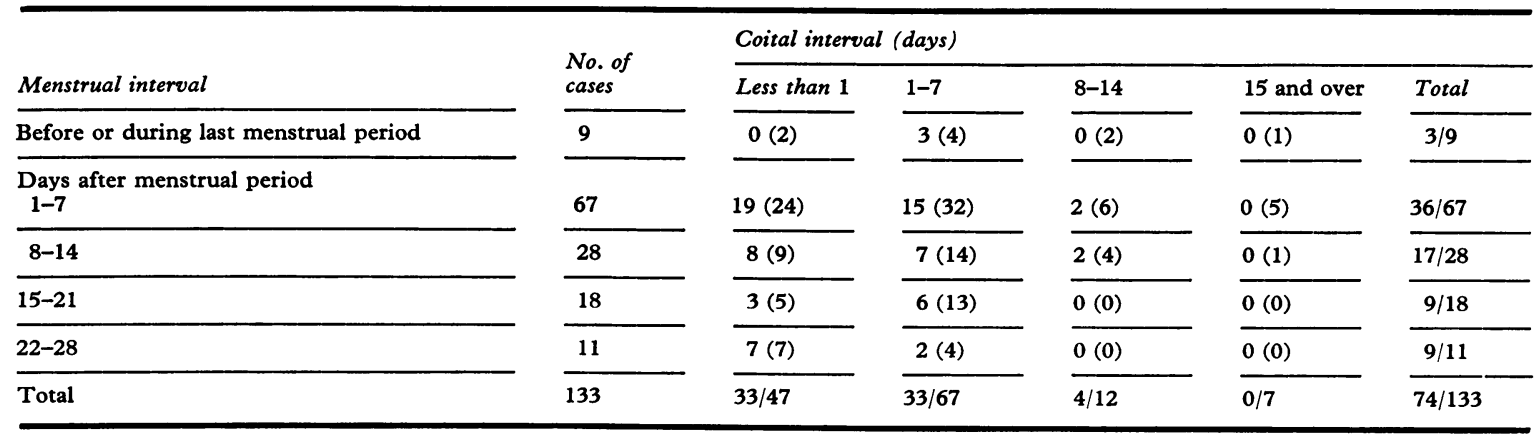


The discovery of sperms in the cervix after menstruation, coitus having taken place on the first day of the menstrual period in one case and in two other cases before menstruation had completely finished, supports the assertion of Smith and Cook (1928). As it was secondary to the routine tests carried out in a venereal disease clinic, this investigation precluded observation of the motility and viability of spermatozoa.

\section{Summary}

In the course of routine genital examination of women in a venereal diseases clinic, smears were examined for spermatozoa. There were 104 women in the case series and the total number of examinations after intercourse was 178. The interval between coitus and examination varied from 2 hours to 21 days. Where possible, the last day of the menstrual period was related to the day of coitus, the longest interval being 28 days after the period in a cycle of 33 days.

Intercourse occurred most frequently in the first week after the menstrual period finished (50 per cent.).

The optimum period for obtaining positive smears was up to 48 hours after coitus.

Sperms were found in the cervix up to 12 days after coitus and in the vagina up to 9 days after. They were also found in the cervix after the menstrual period following coitus before or during the period in three cases.

The time of persistence of sperms in the cervix may be related to coitus in the 2 nd week after the end of the menstrual period but more data are required to find if this is so.

\section{References}

Brit. med. F. (1964a) 'Any Questions', 1, 546

- (1964b) Ibid., 1, 487

Harkness, A. H. (1970) Personal communication

Macleod, J., Martens, F., Silberman, C., and Sobrero, A. J. (1958) In 'Studies on Fertility', ed. R. G. Harrison, p. 41. Blackwell Scientific Publications, Oxford

ROTHSCHILD, LORD (1962) Brit. med. F., 2, 743, 812

SMITH, S., and Cook, H. G. H. (ed.) (1928) 'Taylor's Principles and Practice of Medical Jurisprudence', 8th ed., vol. 2. Churchill, London

\section{La persistance des spermatozoïdes dans le vagin et le col utérin}

SOMMAIRE

A l'occasion de l'examen général de routine de femmes dans une clinique vénéréologique, on rechercha les spermatozoïdes dans les prélèvements. Une série de 104 femmes fut examinée et le total des examens après rapport sexuel fut de 178. L'intervalle entre le coït et l'examen alla de 2 heures à 21 jours. Chaque fois que ceci fut possible, le dernier jour des règles fut confronté au jour du coït; l'intervalle le plus long fut de 28 jours après les règles, lors d'un cycle de 33 jours.

Les rapports sexuels se situèrent le plus fréquemment dans les premières semaines suivant la fin des règles (50 pour cent).

La période optimale pour obtenir des prélèvements positifs s'étendit jusqu'à 48 heures après le coït.

Des spermatozoïdes furent trouvés dans le col jusqu'à 12 jours après le coït et, dans le vagin, jusqu'à 9 jours après. Dans trois cas, ils furent aussi trouvés dans le col après la période menstruelle suivant un coït avant ou pendant les règles.

Le temps de persistance des spermatozoïdes dans le col par rapport au coït peut aller jusqu'à la deuxième semaine après le fin des règles mais des informations supplémentaires sont requises pour préciser s'il en est bien ainsi. 